\title{
EDITORIAL
}

\section{It's a struggle: That's the nature of life}

I haven't written an editorial in a while. Frankly, I haven't had a moment of quiet calm in which to reflect fully enough on a topic where I could spend the appropriate amount of time honing and working through to create a piece that spoke from my heart in a meaningful and eloquent way. Something that could resonate with the readers of Palliative \& Supportive Care. "I've been busy, and have no time for me!!" How many of us say this almost every day? No time to do something for myself, like writing these editorials that replenish my spirit and make me feel whole and connected to life and all of you! I've been busy doing important tasks related to my clinical and research responsibilities at the hospital, and, as all of us who work in similar settings know, there is almost always more to do than what was on your schedule when you arrived at work. Sometimes even what's on the schedule is truly overwhelming, and you can't imagine that you'll get through the day. But we do get through those busy days, and we get through the days where the unexpected crisis has to be dealt with, or when the colleague who is out needs to be covered for, etc. That's just "work life!" When you add to the mix all the concerns and responsibilities of our "personal lives," it can become truly overwhelming. Many of us are caring for older parents who are ill, or dealing with raising children, dealing with a spouse who is out of work or ill; some of us have our own personal health problems. I can relate; I've got all of these going on in my own life, and they take up so much emotional and physical energy.

But this piece is not about "work-life balance" or "self-care," or "living in the moment," or "practicing meditation and mindfulness" in order to relax and center yourself and have a break from the "busyness" of life. Now, please don't get me wrong. All these topics and practices are important and helpful. I try to find ways to keep myself connected to my own body, mind, and spirit, to my loved ones, and to the beauty of life (music, art, James Bond movies). But I recently realized something about the basic nature of life and existence that I had never fully understood or accepted. It was an epiphany, and that's exactly the kind of new idea or perspective I like to share in these editorials.

It recently became very clear to me that very few things remain stable and unchanged for very long. Things are always changing. The nature of the world is one of constant change and renewal. Our children grow and change. We grow older and change. Workplaces change and grow or shrink. Work colleagues come and go. It's not so much the Buddhist concept that everything is "temporary," but it's pretty close. It's more like that the nature of life and work and existence is constant change. My problem, and I suspect a problem for many of us, is that we grew up thinking that once we reached a certain point in life, all would become easier, stable, predictable; controllable. We could coast, because after all, we had worked so hard to achieve and create the lives we now have. But that's not the nature of life: "Life is a constant struggle."

It is indeed a "struggle." By that, I don't necessarily mean that we are constantly battling or fighting or at war. It's a less violent concept. It's a recognition that there are always competing interests in every aspect of our lives and that our lives involve constantly making "choices" from moment to moment. It's an "attitude" as well. It's the choice of whether we take an attitude of despair, demoralization, shame, or helplessness, or an attitude of courage and hope, and engage in the creation of our uncertain futures. The Danish philosopher Søren Kierkegaard (Kierkegaard et al., 1983) wrote a couple hundred years ago that "Life is the constant struggle of being versus nonbeing." From the moment we are aware of our existence, the creation of our lives is a struggle of attitude - to maintain hope, and to remain courageous enough to live life and love and create our life's work, even if we can lose at all of these aspects of life.

Recognizing that life is a "struggle" actually helped me the other day when I was worrying about a work-related problem. I realized that having a problem to solve at work was the "nature of work." Why did I ever expect work to be any different than that? Work is a struggle, and the solving of problems 
is at the core of what makes work so meaningful. Life and love are exactly the same. If there were no challenges or uncertainties in life and love, we wouldn't cherish them as much. Struggle is the nature of life, and it enriches life. Acknowledging that life is a struggle prepares us to face life squarely and work and love realistically. What may be most overwhelming for us is the expectation that there should be no struggle in life.

I've resolved to struggle on! Now when I'm asked "How are you? How's life?" "How's work?" I have an alternate answer to the perfunctory, and often inaccurate, "fine." I now respond, "It's a struggle!" Hopefully, it will be a long, fruitful, and rewarding struggle for us all.

\section{REFERENCE}

Kierkegaard, S., Hong, H. \& Hong, E. (1983). Fear and trembling/repetition. Princeton: Princeton University Press.

WILLIAM BREITBART, M.D. Editor-in-Chief, Palliative \& Supportive Care Chairman, Jimmie C. Holland Chair in Psychiatric Oncology Chief, Psychiatry Service, Department of Psychiatry \& Behavioral Sciences Memorial Sloan Kettering Cancer Center 641 Lexington Avenue, 7th Floor New York, New York 10022, USA E-Mail: Breitbaw@mskcc.org. 